\title{
LEMBAR KERJA PESERTA DIDIK (LKPD) PEMBELAJARAN TEMATIK BERBASIS TIK: PPM BAGI GURU SD HANG TUAH X SEDATI
}

\author{
Cholifah Tur Rosidah*, Ida Sulistyawati, Achmad Fanani, Pana Pramulia \\ Program Studi PGSD Universitas PGRI Adi Buana Surabaya \\ *cholifah@unipasby.ac.id
}

\begin{abstract}
The development of technology is currently one of the opportunities that can be utilized in the field of education to support the learning process. LKPD used in learning in elementary schools can be packaged thematically assisted by ICT by combining lesson content in one or more subjects according to the theme or sub-theme of learning. ICT-based thematic learning worksheets can minimize the use of paper in learning, because instructions, work steps, and other $\angle K P D$ components are displayed through a projector. For this reason, based on the importance of implementing ICT-based learning $L K P D$, the Adi Buana Surabaya PGSD lecturer team carried out a community service activity with the material for the Student Worksheet (LKPD) for ICT-Based Thematic Learning which was delivered to the elementary school teacher Hang Tuah X Sedati. The method of implementing the workshop is by presentation, modeling and simulation accompanied by assignments. Presentation is a method of delivering material systematically by the presenter without using a lot of media. The presentation material is about the preparation of ICT-based thematic learning tools in general, and the Student Worksheet (LKPD) for ICT-based Thematic Learning in particular. The end of the PPM program for the PGSD Study Program at PGRI Adi Buana University in Surabaya was able to solve teacher problems in designing and developing ICT-based learning worksheets in elementary schools, as well as elaborating learning based on the independent learning curriculum.
\end{abstract}

Keywords: $L K P D, I C T$, thematically learning.

\begin{abstract}
Abstrak
Perkembangan teknologi saat ini menjadi salah satu kesempatan yang bisa dimanfaatkan keberadaannya dalam bidang pendidikan untuk menunjang proses pembelajaran. LKPD yang digunakan dalam pembelajaran di SD dapat dikemas secara tematik berbantuan TIK dengan memadukan muatan pelajaran pada satu atau lebih mata pelajaran sesuai dengan tema atau subtema pembelajaran. LKPD pembelajaran tematik berbasis TIK dapat meminimalisasi penggunaan kertas dalam pembelajaran, karena petunjuk, langkah kerja, dan komponen LKPD lainnya ditampilkan melalui proyektor. Untuk itu, berpijak pada pentingnya penerapan LKPD pembelajaran berbasis TIK, tim dosen PGSD Adi Buana Surabaya melakukan suatu kegiatan pengabdian kepada masyarakat dengan materi Lembar Kerja Peserta Didik (LKPD) Pembelajaran Tematik Berbasis TIK yang disampaikan kepada Guru SD Hang Tuah X Sedati. Metode pelaksanaan workshop adalah dengan presentasi, pemodelan dan simulasi disertai tugas. Presentasi merupakan sebuah metode penyampaian materi secara sistematis oleh pemateri tanpa menggunakan banyak media. Bahan presentasi adalah tentang penyusunan perangkat pembelajaran teematik berbasis TIK secara umum, dan Lembar Kerja Peserta Didik (LKPD) Pembelajaran Tematik Berbasis TIK secara khusus. Berakhirnya pelaksanaan program PPM Program Studi PGSD Universitas PGRI Adi Buana Surabaya ini dapat menyelesaikan permasalahan guru dalam merancang dan mengembangkan LKPD pembelajaran berbasis TIK di SD, serta mengelaborasi pembelajaran berdasarkan kurikulum merdeka belajar.
\end{abstract}

Kata Kunci: LKPD, Pembelajaran Tematik, TIK

\begin{tabular}{l|l|l} 
Submitted: $2021-07-28$ & Revised: $2021-07-28$ & Accepted: 2021-07-31
\end{tabular}

\section{Pendahuluan}

Pembelajaran merupakan interaksi antarpeserta didik, peserta didik dengan guru, dan peserta didik dengan sumber belajar pada suatu lingkungan belajar. Pembelajaran tidak saja bermakna transfer pengetahuan dari guru kepada peserta didik, melainkan juga interaksi peserta didik dengan sumber belajar melalui proses mencari atau mengonstruksi pengetahuan oleh peserta didik secara mandiri maupun kelompok. Jika proses mencari atau mengonstruksi pengetahuan tersebut hanya difasilitasi oleh guru maka tentunya guru akan kesulitan untuk memandu setiap peserta didik dengan kecepatan belajar yang beragam. Dengan demikian, guru harus menggunakan sarana penunjang pembelajaran yang dapat memandu setiap peserta didik untuk belajar secara mandiri dalam mengonstruksi pengetahuan sesuai dengan kecepatan belajarnya masing-masing. 
Lembar Kerja Peserta Didik (LKPD) merupakan salah satu sarana yang dapat menunjang kegiatan belajar mengajar untuk membantu dan mempermudah terjadinya interaksi yang aktif dan efektif antara peserta dengan sumber belajar, sehingga dapat meningkatkan hasil belajar mereka. Melalui LKPD, setiap pengalaman atau tugas belajar peserta didik dalam mengonstruksi pengetahuan secara mandiri maupun kelompok dapat dilakukan secara terstruktur dan sistematis. Selain itu, setiap peserta didik dapat menuliskan hasil kerja pada setiap pengalaman atau tugas belajarnya sesuai dengan lintasan belajarnya masing-masing. Lintasan belajar (/earning trajectory) setiap peserta didik tergambar pada jejak kerja atau evidensi yang terekam pada setiap langkah kerja dalam LKPD.

Sukirman dan Djumhana (2006, hlm. 75-78) mengungkapkan bahwa LKPD merupakan suatu bahan ajar cetak yang berupa lembaran-lembaran yang berisi materi, ringkasan dan petunjuk yang harus dilaksanakan oleh peserta didik. Menurutnya, LKPD dapat berbentuk lembaran berisi tugas yang harus dikerjakan oleh peserta didik baik secara mandiri maupun kelompok lengkap dengan petunjuk dan langkah-langkahnya serta mengandung materi pembelajaran penunjang untuk dikuasai oleh peserta didik. Dengan demikian, selain memandu peserta didik untuk melakukan tugas atau pengalaman belajarnya, LKPD berperan sebagai sumber belajar yang menghasilkan informasi atau pengetahuan untuk dikuasai oleh peserta didik.

Iriawan (2016, hlm. 206) menyatakan bahwa LKPD merupakan salah satu sumber belajar yang dapat dikembangkan oleh pendidik sebagai fasilitator dalam kegiatan pembelajaran. LKPD yang disusun dapat dirancang dan dikembangkan sesuai dengan kondisi dan situasi kegiatan pembelajaran yang akan dihadapi peserta didik. Kaitan dengan perannya sebagai sumber belajar, LKPD berisi informasi atau pengetahuan penunjang saja yang dapat membantu peserta didik untuk melakukan tugas dan pengalaman belajarnya untuk menguasai kompetensi tertentu dan mencari atau mengonstruksi informasi atau pengetahuan pokok yang termuat dalam kompetensi dasar. Dengan kata lain, LKPD digunakan selama proses pembelajaran untuk memandu peserta didik dalam menguasai kompetensi tertentu dan bukan dimaksudkan untuk menguji peserta didik tentang penguasaan kompetensi tertentu. Guru harus dapat membedakan antara LKPD dengan lembar evaluasi, karena terdapat banyak LKPD berisi soalsoal untuk menguji peserta didik sehingga cenderung berperan sebagai lembar evaluasi.

Berdasarkan pengertian di atas, LKPD dapat berwujud lembaran berisi petunjuk dan langkah untuk menyelesaikan berbagai tugas belajar yang harus dikerjakan oleh peserta didik selama proses pembelajaran sesuai dengan kompetensi dasar dan tujuan pembelajaran yang ingin dicapai. Dapat dikatakan bahwa LKPD adalah panduan kerja peserta didik selama pembelajaran berlangsung untuk mempermudah peserta didik dalam melaksanakan pembelajaran untuk menguasai kompetensi tertentu. Dengan demikian, lembar kerja peserta didik sangat berperan dalam pembelajaran karena dapat meningkatkan aktivitas belajar peserta didik untuk belajar mandiri dan belajar memahami serta menjalankan suatu tugas tertulis.

Perkembangan teknologi saat ini menjadi salah satu kesempatan yang bisa dimanfaatkan keberadaannya dalam bidang pendidikan untuk menunjang proses pembelajaran. Terlebih di Era Revolusi Industri 4.0 mengharuskan peserta didik untuk terbuka terhadap perkembangan Teknologi Informasi dan Komunikasi (TIK) dan sejalan dengan kebijakan Permendikbud Nomor 37 Tahun 2018 Pasal 2A ayat (1) tentang integrasi pembelajaran TIK di SD. Oleh karena itu, LKPD yang digunakan dalam pembelajaran di SD dapat dikemas secara tematik berbantuan TIK dengan memadukan muatan pelajaran pada satu atau lebih mata pelajaran sesuai dengan tema atau subtema pembelajaran (Abdullah, dkk, 2017).

LKPD pembelajaran tematik berbasis TIK dapat meminimalisasi penggunaan kertas dalam pembelajaran, karena petunjuk, langkah kerja, dan komponen LKPD lainnya ditampilkan melalui proyektor. LKPD pembelajaran tematik berbasis TIK dapat berbentuk LKPD Eksploratif, LKPD Eksperimental, dan LKPD Latihan Psikomotorik yang dikemas dengan tampilan yang menarik 
berbantuan perangkat lunak untuk memotivasi peserta didik dalam belajar secara aktif dan mandiri. Perangkat lunak yang dapat digunakan untuk mengembangkan LKPD pembelajaran tematik berbasis TIK, di antaranya powerpoint, corel draw, adobe ilustrator, adobe animate, photoshop, dan lain-lain (Rachmadtullah, dkk, 2020; Candra, 2021).

Selain dapat dikemas secara menarik, LKPD pembelajaran tematik berbasis TIK juga dapat dikembangkan dalam bentuk elektronik atau e-LKPD yang dapat diakses melalui internet sehingga peserta didik dapat belajar dimanapun dan kapanpun dengan mengakses LKPD dengan bebas tanpa harus diberikan oleh guru. Tentunya peran guru dan orang tua sangat penting dalam mengawasi peserta didik dalam memanfaatkan e-LKPD.

Berpijak pada pentingnya penerapan LKPD pembelajaran berbasis TIK, dengan demikian tim dosen PGSD Adi Buana Surabaya yang berpengalaman dalam penelitian melakukan suatu kegiatan pengabdian kepada masyarakat yang berjudul "Lembar Kerja Peserta Didik (LKPD) Pembelajaran Tematik Berbasis TIK: PPM Bagi Guru SD Hang Tuah X Sedati".

Berdasarkan latar belakang masalah di atas, maka tujuan pengabdian pada masyarakat yang dilakukan dosen PGSD Universitas PGRI Adi Buana Surabaya, yaitu mengenalkan dan memahamkan Lembar Kerja Peserta Didik (LKPD) Pembelajaran Tematik Berbasis TIK kepada Guru SD Hang Tuah X Sedati.

Berakhirnya pelaksanaan program PPM Program Studi PGSD Fakultas Pedagogi dan Psikologi Universitas PGRI Adi Buana Surabaya diharapkan mampu menyelesaikan permasalahan guru dalam menyusun Lembar Kerja Peserta Didik (LKPD) Pembelajaran Tematik Berbasis TIK. Luaran yang akan dihasilkan dari pelaksanaan pengabdian masyarakat ini berupa laporan, poster, dan artikel ilmiah.

Kelompok sasaran dalam kegiatan Pengabdian Kepada Masyarakat (PPM) ini adalah guru SD Hang Tuah X Sedati Sidoarjo. Kondisi profil kelompok sasaran memberikan gambaran bahwa potensi guru SD di daerah tersebut telah sarjana, sehingga memungkinkan lebih mudah untuk ditingkatkan dan diberdayakan menjadi lebih potensial dan profesional. Kondisi saat ini di Revolusi Industri 4.0, penerapan pembelajaran berbasis TIK menjadi suatu kewajiban yang dilakukan guru agar proses pembelajaran berjalan sesuai rencana dan mendapatkan hasil optimal. Selain itu juga pelaksanaan pembelajaran berbasis TIK dapat menjadi sarana guru dalam menjadikan pendidik yang profesional.

Tabel 1. Potensi Guru SD di SDN Margorejo I Kota Surabaya

\begin{tabular}{|c|c|c|}
\hline No. & Bidang Garap dan Sasaran & Potensi Sekolah \\
\hline 1 & $\begin{array}{l}\text { Menetapkan strategi yang tepat untuk } \\
\text { memberikan pemahaman dan } \\
\text { motivasi terhadap pentingnya Lembar } \\
\text { Kerja Peserta Didik (LKPD) } \\
\text { Pembelajaran Tematik Berbasis TIK }\end{array}$ & $\begin{array}{l}\text { Sebagian guru belum memahami } \\
\text { pentingnya Lembar Kerja Peserta Didik } \\
\text { (LKPD) Pembelajaran Tematik Berbasis } \\
\text { TIK }\end{array}$ \\
\hline 2 & $\begin{array}{l}\text { Perlu diadakan pelatihan tentang } \\
\text { penyusunan Lembar Kerja Peserta } \\
\text { Didik (LKPD) Pembelajaran Tematik } \\
\text { Berbasis TIK, sehingga guru dapat } \\
\text { meningkatkan kualitas pembelajaran. }\end{array}$ & $\begin{array}{l}\text { Selama ini sebagian guru belum } \\
\text { maksimal dalam menyusun dan } \\
\text { menerapkan Lembar Kerja Peserta Didik } \\
\text { (LKPD) Pembelajaran Tematik Berbasis } \\
\text { TIK. }\end{array}$ \\
\hline
\end{tabular}

\section{Metode}

Metode pelaksanaan workshop adalah dengan presentasi, pemodelan dan simulasi disertai tugas. Presentasi merupakan sebuah metode penyampaian materi secara sistematis oleh pemateri tanpa menggunakan banyak media. Bahan presentasi adalah tentang penyusunan perangkat pembelajaran teematik berbasis TIK secara umum, dan Lembar Kerja Peserta Didik (LKPD) 
Pembelajaran Tematik Berbasis TIK secara khusus. Kemudian instruktur berdiskusi dengan guruguru, dengan memberikan contoh-contoh Lembar Kerja Peserta Didik (LKPD) Pembelajaran Tematik Berbasis TIK yang telah dikembangkan sebelumnya. Metode pemodelan merupakan metode memberikan contoh-contoh kepada peserta sehingga peserta dapat menirunya. Serta tim meminta guru untuk mendesain Lembar Kerja Peserta Didik (LKPD) Pembelajaran Tematik Berbasis TIK sesuai dengan kelas dan pembelajaran guru masing-masing. Metode penugasan adalah metode memberikan tugas kepada peserta agar dapat dikerjakan diluar waktu workshop. Instruktur menilai hasil kerja guru. Pada tahap akhir, guru diberikan angket kepuasan untuk menghitung feedback guru terhadap pelaksanaan workshop. Berikut mekanisme pelaksanaan kegiatan PPM.

Tabel 2. Materi Pembelajaran, Pelatihan dan Pelaksana

\begin{tabular}{|c|c|c|c|}
\hline No. & Materi & & Pelaksana \\
\hline 1. & $\begin{array}{ll}\text { a. } & \text { Hakikat LKPD } \\
\text { b. } & \text { Jenis-jenis LKPD }\end{array}$ & & 1. Cholifah Tur Rosidah, S.Pd., M.Pd. \\
\hline 2. & $\begin{array}{l}\text { LKPD Pembelajaran } \\
\text { Berbasis TIK }\end{array}$ & Tematik & 1. Ida Sulistyawati, S.H., M.Pd. \\
\hline 3. & $\begin{array}{l}\text { Prosedur Penyusunan } \\
\text { Pembelajaran Tematik } \\
\text { TIK }\end{array}$ & $\begin{array}{r}\text { LKPD } \\
\text { Berbasis }\end{array}$ & 1. Drs. Achmad Fanani, S.T. M.Pd. \\
\hline 4. & $\begin{array}{lr}\text { Penggunaan LKPD } & \text { Pem } \\
\text { Tematik Berbasis } & \text { TIK } \\
\text { Pembelajaran di SD } & \end{array}$ & $\begin{array}{r}\text { dalamaran } \\
\text { dalam }\end{array}$ & 2. Pana Pramulia, S.Pd., M.Pd. \\
\hline
\end{tabular}

\section{Hasil dan Pembahasan}

Kegiatan PPM dengan judul "Lembar Kerja Peserta Didik (LKPD) Pembelajaran Tematik Berbasis TIK: PPM Bagi Guru SD Hang Tuah X Sedati" dilaksanakan dalam dua kali, yaitu pada tanggal 1 April 2021 dan tanggal 2 April 2021. Rinciannya sebagai berikut.

1. Pertemuan Pertama

Pelaksanaan kegiatan Pengabdian Pada Masyarakat (PPM) ini dilaksanakan secara daring melalui aplikasi Zoom Cloud, karena pemerintah masih menerapkan PPKM, sehingga tidak memungkinkan melaksanakan pertemuan secara langsung (luring). Secara keseluruhan, kegiatan tersebut dilaksanakan pada 1 April 2021 - 2 April 2021. Kegiatan Pengabdian Pada Masyarakat ini dilaksanakan dalam bentuk workshop dengan diawali pemaparan materi, diskusi, dan workshop dengan pendampingan dosen saat kerja kelompok. Pelaksanaan pertama dilaksanakan pada tanggal 1 April 2021, pelaksanaan kedua pada tanggal 2 April 2021, dan seluruh pemateri dan beberapa mahasiswa yang terlibat hadir dalam workshop. Workshop dibagi dalam dua pertemuan untuk empat materi. Pertemuan pertama kegiatan PPM berupa penyampaian materi untuk pendalaman ( 2 materi) dan pertemuan kedua bersifat workshop sebagai bentuk pendalaman dan pengembangan ( 2 materi). Pertemuan pertama materi satu dimulai pukul 08.00 sampai dengan pukul 09.30. Materi dua dimulai pukul 09.30 sampai dengan pukul 12.00. Kegiatan PPM tersebut dirinci sebagai berikut.

a) Hakikat LKPD

Materi Hakikat LKPD disampaikan Cholifah Tur Rosidah, S.Pd., M.Pd. Ruang lingkup materi berkaitan dengan pengertian, prinsip, jenis-jenis, dan fungsi LKPD. Materi disampaikan melalui power point dan $100 \%$ berupa teori untuk pemahaman. Cholifah Tur Rosidah, S.Pd., M.Pd., mempresentasikan mengenai Hakikat LKPD selama enam puluh menit (08.00 - 09.00). Sisa waktu tiga puluh menit digunakan untuk diskusi dan tanya jawab, serta interaksi antara satu peserta dengan peserta lainnya. Peserta yang mengikuti diskusi tanya jawab dapat dikatakan aktif dan interaktif. Pada materi pertama ini ada sepuluh pertanyaan yang dibagi dalam dua 
termin. Masing-masing termin terdapat dua pertanyaan. Pertanyaan dari peserta cenderung mengarah pada LKPD pembelajaran daring. Materi pertama ini diakhiri pukul 09.30.

b) LKPD Pembelajaran Tematik Berbasis TIK

Materi LKPD Pembelajaran Tematik Berbasis TIK disampaikan Ida Sulistyawati, S.H., M.Pd. Pada kegiatan ini materi yang disampaikan berkaitan dengan LKPD Eksploratif, LKPD Eksperimental, dan LKPD Latihan Psikomotorik. Materi yang dijelaskan dijelaskan dikaitkan langsung dengan era revolusi industri yang terbuka terhadap TIK. Selain itu, materi juga menjelaskan tentang Permendikbud Nomor 37 Tahun 2018 mengenai integrasi pembelajaran TIK di SD. Materi disampaikan Ida Sulistyawati, S.H., M.Pd., selama enam puluh menit (09.30 - 10.30). Pada pukul 10.30 - 11.30 digunakan untuk penugasan kepada peserta membuat LKPD sesuai dengan arahan tutor. Sisa waktu tiga puluh menit digunakan untuk diskusi dan tanya jawab. Tanya jawab dibagi menjadi dua termin. Termin pertama lima belas menit dan termin dua lima belas menit. Masing-masing termin tanya jawab terdapat tiga penanya. Pertanyaan yang disampaikan peserta langsung berkaitan dengan LKPD berbasis TIK. Materi dua ini berakhir pukul 12.00 .

2. Pertemuan Kedua

Pelaksanaan kegiatan Pengabdian Pada Masyarakat (PPM) pertemuan kedua ini tetap dilaksanakan secara daring melalui aplikasi zoom cloud dan tutorial melalui Grup WhatsApp. Pelaksanaan kedua dilaksanakan pada tanggal 2 April 2021 dan seluruh pemateri dan beberapa mahasiswa yang terlibat hadir dalam workshop. Workshop dibagi dalam dua sesi. Sesi pertama dimulai pukul 08.00 sampai dengan pukul 09.30. Sesi dua dimulai pukul 09.30 sampai dengan pukul 12.00 . Berbeda dengan pertemuan pertama yang bersifat $80 \%$ teoretis dan $20 \%$ praktis, pada pertemuan kedua ini materi bersifat praktis walaupun masih ada sedikit teori. Artinya, setelah peserta mendapatkan materi, kemudian peserta berdiskusi, mempresentasikan hasil diskusinya, bekerja mandiri, dan mempresentasikan hasil kerja mandirinya. Pemateri disamping memberikan bahan, juga bertindak sebagai tutor workshop atau teman diskusi. Kegiatan PPM tersebut dirinci sebagai berikut.

a) Prosedur Penyusunan LKPD Pembelajaran Tematik Berbasis TIK

Pemateri yang bertugas menyampaikan materi dan sekaligus sebagai tutor workshop pada sesi pertama, yaitu Drs. Achmad Fanani, S.T. M.Pd. Pada pertemuan ini pemateri memberi tugas kembali kepada para peserta untuk menyusun LKPD Pembelajaran Tematik Berbasis TIK. Dasar penugasan sesuai dengan materi yang disampaikan pada pertemuan sebelumnya. Penugasan dimulai pukul $08.00-08.30$, kemudian dilanjutkan presentasi pada pukul 08.30 - 09.00. Pukul 09.00 presentasi selesai, kemudian dilanjutkan refleksi dan diskusi. Setelah itu peserta PPM diberi waktu untuk merefleksikan hasil presentasinya melalui esai pendek, kemudian dikumpulkan melalui Grup WhatsApp dengan file yang diberi nama sesuai nama guru yang mengumpulkan. Setelah itu, tutor workshop memberikan pengarahan terkait bahan dan isi presentasi dari peserta. Pukul 09.30 tepat materi media pembelajaran berbasis TIK selesai.

b) Penggunaan LKPD Pembelajaran Tematik Berbasis TIK dalam Pembelajaran di SD

Pertemuan kedua sesi tiga peserta melakukan workshop tentang penggunaan LKPD pembelajaran tematik berbasis TIK dalam pembelajaran di SD. Pada sesi ini, Pana Pramulia, S.Pd., M.Pd. bertugas sebagai tutor workshop, dan sekaligus menjadi pemandu. Workshop dilaksanakan selama enam puluh menit $(09.30-10.30)$. Selama enam puluh menit tersebut, sacara mandiri seluruh peserta memperbaiki LKPD pembelajaran berbasis TIK yang dibuat berdasarkan arahan dari tutor. Penyusunan LKPD pembelajaran berbasis TIK dalam pembelajaran di SD ini didasarkan pada kesalahan penyusunan sesi sebelumnya, serta dikaitkan dengan kurikulum 2013 dan kurikulum merdeka belajar. Pukul 10.30 - 11.30 peserta secara mandiri mempresentasikan hasil kerjanya. Pana Pramulia, S.Pd., M.Pd., menjelaskan 
kembali dan memperdalam pemahaman mengenai LKPD pembelajaran berbasis TIK dalam pembelajaran di SD kepada peserta PPM. Pukul 11.30 - 12.00 dilaksanakan diskusi dan tanya jawab. Pemateri workshop menjadi pemandu sesi diskusi. Berakhirnya diskusi tentang materi penggunaan LKPD pembelajaran berbasis TIK dalam pembelajaran di SD, maka berakhir pula rangkaian kegiatan PPM yang berjudul "Lembar Kerja Peserta Didik (LKPD) Pembelajaran Tematik Berbasis TIK: PPM Bagi Guru SD Hang Tuah X Sedati".

\section{Kesimpulan}

Lembar Kerja Peserta Didik (LKPD) merupakan salah satu sarana yang dapat menunjang kegiatan belajar mengajar untuk membantu dan mempermudah terjadinya interaksi yang aktif dan efektif antara peserta dengan sumber belajar, sehingga dapat meningkatkan hasil belajar mereka. Selain itu, setiap peserta didik dapat menuliskan hasil kerja pada setiap pengalaman atau tugas belajarnya sesuai dengan lintasan belajarnya masing-masing. Lintasan belajar (/earning trajectory) setiap peserta didik tergambar pada jejak kerja atau evidensi yang terekam pada setiap langkah kerja dalam LKPD. Perkembangan teknologi saat ini menjadi salah satu kesempatan yang bisa dimanfaatkan keberadaannya dalam bidang pendidikan untuk menunjang proses pembelajaran. Terlebih di Era Revolusi Industri 4.0 mengharuskan peserta didik untuk terbuka terhadap perkembangan Teknologi Informasi dan Komunikasi (TIK). LKPD pembelajaran tematik berbasis TIK dapat meminimalisasi penggunaan kertas dalam pembelajaran, karena petunjuk, langkah kerja, dan komponen LKPD lainnya ditampilkan melalui proyektor. LKPD pembelajaran tematik berbasis TIK dapat berbentuk LKPD Eksploratif, LKPD Eksperimental, dan LKPD Latihan Psikomotorik yang dikemas dengan tampilan yang menarik berbantuan perangkat lunak untuk memotivasi peserta didik dalam belajar secara aktif dan mandiri.

Berdasarkan hal tersebut, tim dosen Program Studi PGSD Universitas PGRI Adi Buana Surabaya melaksanakan PPM mengenalkan dan memahamkan LKPD Pembelajaran Berbasis TIK kepada Guru SD Hang Tuah X Sedati. PPM dilaksanakan selama dua hari (dua pertemuan). Materi yang disampaikan pada pertemuan pertama meliputi (1) Hakikat LKPD; dan (2) LKPD Pembelajaran Tematik Berbasis TIK. Materi yang disampaikan pada pertemuan kedua meliputi (1) Prosedur Penyusunan LKPD Pembelajaran Tematik Berbasis TIK; dan (2) Penggunaan LKPD Pembelajaran Tematik Berbasis TIK dalam Pembelajaran di SD.

Berakhirnya pelaksanaan program PPM Program Studi PGSD Universitas PGRI Adi Buana Surabaya yang berjudul Lembar Kerja Peserta Didik (LKPD) Pembelajaran Tematik Berbasis TIK: PPM Bagi Guru SD Hang Tuah X Sedati ini dapat menyelesaikan permasalahan guru dalam merancang dan mengembangkan LKPD pembelajaran berbasis TIK di SD, serta mengelaborasi pembelajaran berdasarkan kurikulum merdeka belajar. Hal tersebut dibuktikan dengan pemahaman berdasarkan presentasi dan tugas yang dilakukan peserta. Untuk pendalaman, berikutnya akan dilanjutkan mengenai aplikasi pembelajaran tematik berbasis TIK.

PPM yang dilaksanakan oleh dosen PGSD Universitas PGRI Adi Buana Surabaya ini merupakan tahap ketiga. Pada tahap berikutnya, peserta akan mendapatkan materi yang lebih praktis, sehingga dapat membuat LKPD pembelajaran berbasis TIK serta dapat mengaplikasikan pembelajaran tematik berbasis TIK. Maka dari itu, saran bagi peserta dan pemateri agar lebih siap pada pelaksanaan tahap berikutnya.

\section{DAFTAR PUSTAKA}

Abdullah, A. G., Hamidah, I., Aisyah, S., Danuwijaya, A. A., Yuliani, G., \& Munawaroh, H. S. (Eds.). (2017). Ideas for 21st Century Education: Proceedings of the Asian Education Symposium (AES 2016), November 22-23, 2016, Bandung, Indonesia. Routledge.

Anderson, L. W. dan Krathwohl, D. R. (2001). A Taxonomy for Learning, Teaching, and Assessing: A Revision of Bloom's Taxonomy of Educational Objectives. New York: Longman. 
Arends, R. I. (2009). Learning to Teach. New York: McGraw Hill.

Candra, F. A. (2021). Pengembangan Media Pembelajaran Tematik Berbasis TIK Di Sekolah Dasar. In Prosiding Seminar Nasional Pembelajaran Bahasa dan Sastra Indonesia (SemNas PBSI)3 (pp. 99-110). FBS Unimed Press.

Darmawan, D. dkk. (2008). Dasar Teknologi Informasi dan Komunikasi. Bandung: UPI Press.

Iriawan, S. B. (2016). Appropriate Teaching Method as A Source of Students'Success in Learning. MUK Publication: Global and Stochastic Analysis, 3 (3). 203-214.

Nasution, Z. (2001). Perkembangan Teknologi Komunikasi. Jakarta: Universitas Terbuka.

Rachmadtullah, R., Yustitia, V., Setiawan, B., Mahya Fanny, A., Pramulia, P., Susiloningsih, W., ... \& Ardhian, T. (2020). The Challenge Of Elementary School Teachers To Encounter Superior Generation In The 4.0 Industrial Revolution: Study Literature. International Journal of Scientific \& Technology Research, 9(4), 1879-1882.

Sukirman, D. dan Djumhana, N. (2006). Perencanaan Pembelajaran. Bandung: UPI Press. 